\title{
Functional Masculinization of Female Guppies, Poecilia reticulata, Influenced by Methyltestosterone before Birth
}

\author{
Hiroya TAKaHaShi* \\ (Received September 5, 1974)
}

\begin{abstract}
In order to obtain female unisexual broods of the guppy, Poecilia reticulata, the possibility of sex reversal of genetic female offspring was examined by daily oral administration of methyltestosterone (MT, $300-500 \mu \mathrm{g} / \mathrm{g}$ diet) to gravid females during various periods of gestation. Treatments with $400 \mu \mathrm{g} \mathrm{MT}$ initiated 8 to 10 days prior to parturition and lasting up to the end of gestation most successfully caused the birth of all male young, and resultant sex-reversed males were evidenced to be fertile to yield all female broods when mated naturally with normal females. Treatments for longer periods of gestation or with higher dosage of $\mathrm{MT}$ were liable to bring about a delayed and obstructed parturition accompanying the birth of dead embryos and an infertility of sex-reversed males. This manner of hormone application was considered to be more facile and stable as compared with the method reported previously in obtaining sex-reversed, functional males of the guppy.
\end{abstract}

In a previous paper ${ }^{11}$, the present writer reported that the oral administration of methyltestosterone to female guppies after birth induces only partial masculinization of germ cells and concurrently causes varying deficiencies in the morphogenesis of the gonoduct system. On the other hand, DzwILLO ${ }^{2}$ achieved sex reversal of genetic female offspring into functional males by treating their maternal guppies for $24 \mathrm{hr}$ with methyltestosterone, added to rearing water at a concentration of $3 \mathrm{mg}$ per liter water, 22 days after the last parturition. Although his method is certainly effective in inducing the sex reversal of the guppy, some difficulties seem to lie in that the treatment exerted harmful influences, such as an inevitable delay of gestation and an impediment in parturition, on affected maternal fish, and in that the resultant sex-reversed males could not successfully fertilize normal females when mated naturally. ${ }^{2)}$ Furthermore, the critical period for an effective treatment was much limited ${ }^{3}$, and it seems to be rather difficult to determine the period precisely inasmuch as the brood intervals may vary widely with different times of birth in the guppy.

The present report extends DzwILLo's findings to establish a more facile and stable way of androgen treatment in obtaining a complete and functional masculinization of genetic female offspring by means of oral administration of methyltestosterone to pregnant guppies. It is the final aim of the present study to get female unisexual broods of the guppy as a material for experimental analyses of the sexuality in the guppy.

\footnotetext{
* Laboratory of Freshwater Fish-Culture, Faculty of Fisheries, Hokkaido University, Hakodate. (高楆 裕哉：北海道大学水産学部淡水增殭学教室)
} 


\section{Material and Methods}

Guppies, Poecilia reticulata, of a yellow variety ${ }^{1 /}$ bred in the laboratory were employed for the present study. Gravid females numbered individually were each placed in its respective aquarium with about 9 liters of constantly aerated water at $23-25^{\circ} \mathrm{C}$ under the natural conditions of light and darkness. Their broods were isolated from the maternal fish the day following birth and kept on ordinary diets in identical conditions to determine their sex distribution which served as controls. The females after parturition were reared successively in the same aquaria for hormonal treatments, without further mating with males because the guppy is capable of accomplishing at least five successive parturitions after one copulation. ${ }^{4,5}$ They were fed daily a commercial dry food. The aquaria were generally cleaned once a week.

Diets containing methyltestosterone (MT) at dosages of 300,400 and $500 \mu \mathrm{g}$ per $\mathrm{g}$ diet were prepared in the same manner as reported previously. ${ }^{11}$ Daily feeding of the androgen-containing diet was commenced at various days after the last parturition and continued until the day of the next parturition or for a constant period of 6 days, as recorded in Tables 1-3. After the delivery of affected broods, the females were removed, the aquaria were cleaned, and the broods were maintained on an ordinary diet to mature sexually. Some guppies of these androgen-affected broods, especially those regarded as sex-reversed males, were sacrificed at various ages for the histological examinations of their gonads.

\section{Results}

Mature male guppies of the present variety are normally dressed with several orangered spots on both sides of the trunk and caudal peduncle. The pigmentation is certainly inherited through Y chromosome-linked gene(s), thus being specific to the genetic male sex (XY), and is induced to occur by the action of androgens exclusively in genetic males." Accordingly, in the present study, adult guppies with well-developed gonopodia and without any pigmentation of the male pattern were regarded as sex-reversed males with female chromosomal constitution (XX).

A series of preliminary experiments showed that no modification of sex was attainable in the young born from the females treated with MT at dosages of 50 and $100 \mu \mathrm{g}$ even when the treatments lasted through almost the whole period of gestation.

By $300 \mu \mathrm{g} \mathrm{MT} \mathrm{(Table} \mathrm{1-A),} \mathrm{a} \mathrm{13-day} \mathrm{treatment} \mathrm{from} 15$ days after parturition (No. 6017) was also ineffective, but a 17-day treatment from 10 days (No. 6018) produced 4 sex-reversed males among 18 genetically female offspring, together with 21 genetic males. The sex-reversed males were evidenced to be fertile when crossed with virgin females, and resultant broods invariably comprised all females, which substantiated the functional sex 
Table 1. Sex distribution of guppies born from females treated with methyltestosterone (MT) during gestation up to the day of parturition

\begin{tabular}{|c|c|c|c|c|c|c|c|c|c|c|}
\hline \multirow{2}{*}{$\begin{array}{l}\text { Fish } \\
\text { No. }\end{array}$} & \multicolumn{3}{|c|}{$\begin{array}{l}\text { Sex distribution } \\
\text { in control brood*1 }\end{array}$} & \multicolumn{2}{|c|}{$\begin{array}{c}\text { Days after the last } \\
\text { parturition }\end{array}$} & \multirow{2}{*}{$\begin{array}{c}\text { Duration } \\
\text { of } \\
\text { medication } \\
\text { (days) }\end{array}$} & \multicolumn{4}{|c|}{$\begin{array}{l}\text { Sex distribution in } \\
\text { affected brood*1 }\end{array}$} \\
\hline & $\begin{array}{l}\text { (No. } \\
\text { born) }\end{array}$ & $\mathbf{F}$ & M & $\begin{array}{c}\text { at start } \\
\text { of medication }\end{array}$ & at parturition & & $\begin{array}{c}\text { (No. } \\
\text { born) }\end{array}$ & $\mathrm{F}$ & $\mathrm{M}(\mathrm{F})$ & M \\
\hline \multicolumn{11}{|c|}{ A. $300 \mu \mathrm{g} \mathrm{MT} / \mathrm{g}$ diet } \\
\hline 6024 & (29) & 12 & 16 & 6 & 23 & 18 & (16) & 0 & 9 & 7 \\
\hline 6018 & $(25)$ & 15 & 10 & 10 & 26 & 17 & (39) & 14 & 4 & 21 \\
\hline 6017 & (18) & 10 & 8 & 15 & 27 & 13 & (33) & 14 & 0 & 18 \\
\hline \multicolumn{11}{|c|}{ B. $400 \mu \mathrm{g} \mathrm{MT} / \mathrm{g}$ diet } \\
\hline 6021 & $(17)$ & 10 & 6 & 8 & 28 & 21 & (9) & 0 & 6 & 3 \\
\hline 6022 & (25) & 11 & 14 & 11 & 24 & 14 & $(46)$ & 0 & 26 & 20 \\
\hline 6023 & (9) & 7 & 2 & 16 & 25 & 10 & (51) & 2 & 20 & 29 \\
\hline 6039 & (83) & 15 & 8 & 17 & 26 & 10 & (35) & 0 & 14 & 13 \\
\hline 6041 & $(28)$ & 12 & 9 & 18 & 22 & 5 & $(50)$ & 6 & 18 & 20 \\
\hline 6038 & (45) & 11 & 10 & 19 & 21 & 3 & (42) & 19 & 0 & 23 \\
\hline 6040 & (14) & 6 & 8 & 19 & 31 & 13 & (24) & 0 & 6 & 16 \\
\hline $6042 * 2$ & $(-)$ & - & - & 19 & 26 & 8 & $(16)$ & 0 & 3 & 7 \\
\hline \multicolumn{11}{|c|}{ C. $500 \mu \mathrm{g} \mathrm{MT} / \mathrm{g}$ diet } \\
\hline 6020 & $(40)$ & 38 & 37 & 7 & 29 & 23 & (10) & 0 & 7 & 3 \\
\hline 6019 & (39) & 38 & 32 & 8 & 29 & 22 & ( 3$)$ & 0 & 2 & 1 \\
\hline
\end{tabular}

*1 Sex distribution in each brood was examined in the fish aged more than 50 days following birth. $F$, female; $M(F)$, sex-reversed male $(X X) ; M$, genetic male (XY).

*2 Many newly delivered fish of the control brood became the prey of the adult and were discarded from the result.

reversal of these genetic females. A female (No. 6024) treated with $300 \mu \mathrm{g}$ MT from 6 postpartal days for 18 days up to the next parturition gave birth to 16 viable young and some dead ones. The viable young were all males, out of which 9 being recognized as sex-reversed males. Their gonopodia appeared to be somewhat atypical in shape. These males were mated with virgin females, but failed to fertilize them in most cases. They were provided with testes displaying normal histoarchitecture, but were deficient in sperm duct formation in the caudalmost region of the duct system. The treated female (No. 6024) was sacrificed the day after parturition and her ovary was examined histologically: it was noticed that many embryos remained undelivered in the ovarian cavity and in the ovarian follicles.

Two gravid females administered with $500 \mu \mathrm{g}$ MT from 7 and 8 postpartal days until the next parturition bore all male offspring on the 29 th postpartal day (Table 1-C). However, the size of the obtained broods was admittedly smaller than that of the previous, control broods, and many dead embryos were found in the ovaries of these females autopsied 2 days after parturition. Moreover, the brood interval seemed to be longer than usual, inasmuch as the interval between broods of normal female guppies of the present variety was $26.00 \pm 1.50$ days as the average of 9 broods under identical rearing con- 
ditions. Sex-reversed males of the affected broods failed to fertilize normal females, although they were furnished with histologically well-organized testes and were capable of releasing intact spermatophores when stripped artificially.

Other 8 gravid females were treated with $400 \mu \mathrm{g}$ MT during various periods of their gestation as shown in Table 1-B. The treatments started 8 and 11 postpartal days and lasting until the day of the next parturition (Nos. 6021 and 6022) effected the sex reversal of all genetic female offspring into males, though the long-lasting treatments made the females give birth to many dead fish along with viable males. Many of the sex-reversed, mature males of these broods were equipped with gonopodia of a somewhat atypical shape and, histologically, their sperm duct system revealed a poor development. Pregnant females affected by $400 \mu \mathrm{g}$ MT beginning from 16 to 19 postpartal days successfully yielded all male offspring when the hormone administration was continued for 8 to 13 days up to the next parturition, except the fish No. 6023 which bore 2 females together with 20 sex-reversed and 29 normal males. Sex-reversed males of these broods were normal in the formation of gonopodia and in histological aspects of their testes. Some of them were each mated naturally with virgin females and satisfactorily fertilized them to produce all female broods without exception. The treatment lasting for only 3 days before parturition in the female No. 6038 was utterly without effect on the sex of her young, and that for 5 days in the female No. 6041 was only efficient to evoke a functional masculinization of some of the genetic females.

The females treated with MT were maintained on an ordinary diet subsequently after parturition, isolated from males, but never executed successive parturition for as long as 2 months. Histological examination of their ovaries disclosed the absence of spermatozoa which were to be stored in the delles of maturing and matured ovarian follicles. The fish No. 6042 was mated again with a sex-reversed male 8 days following parturition, and was successfully delivered of 27 all females 39 days after the mating.

In the second series of experiments, the masculinizing effect of $400 \mu \mathrm{g}$ MT in relation to the time and duration of treatment was reaffirmed by using 7 gravid females which had given birth to female unisexual broods as a result of the mating with sex-reversed males (Table 2). Daily administration of MT to these females was mostly begun 13 to 15 days after the last parturition, resulting in the production of their young of all males when the treatment was continued for 6 to 10 days until the day of the next parturition. As was expected, all of these males were undoubtedly sex-reversed ones, never displaying the occurrence of male sexual coloration when matured, and were proved to be fertile by mating tests. Young of a brood affected by the treatment for the last 12 days of prenatal life (No. 6052) were also sex-reversed males except for a female which had a poorly developed ovary. However, a defect in sperm duct in the caudalmost region of the duct system was remarked in many of those examined 50 days after birth. Treatments 
Table 2. Sex distribution of guppies of female unisexual broods born from females treated with methyltestosterone ( $400 \mu \mathrm{g} / \mathrm{g}$ diet) during gestation until the day of parturition

\begin{tabular}{|c|c|c|c|c|c|c|c|c|c|c|}
\hline \multirow{2}{*}{$\begin{array}{l}\text { Fish } \\
\text { No. }\end{array}$} & \multicolumn{3}{|c|}{$\begin{array}{l}\text { Sex distribution } \\
\text { in control brood* }\end{array}$} & \multicolumn{2}{|c|}{$\begin{array}{l}\text { Days after the last } \\
\text { parturition }\end{array}$} & \multirow{2}{*}{$\begin{array}{l}\text { Duration } \\
\text { of } \\
\text { medication } \\
\text { (days) }\end{array}$} & \multicolumn{4}{|c|}{$\begin{array}{l}\text { Sex distribution in } \\
\text { affected brood* }\end{array}$} \\
\hline & $\begin{array}{l}\text { (No. } \\
\text { born) }\end{array}$ & $F$ & $\bar{M}$ & $\begin{array}{l}\text { at start } \\
\text { of medication }\end{array}$ & at parturition & & $\begin{array}{l}\text { (No. } \\
\text { born) }\end{array}$ & $F$ & $\mathrm{M}(\mathrm{F})$ & $\mathrm{M}$ \\
\hline 6052 & $\overline{(44)}$ & 44 & 0 & 13 & 24 & 12 & (35) & 1 & 31 & 0 \\
\hline 6053 & (20) & 20 & 0 & 13 & 21 & 9 & (22) & 0 & 22 & 0 \\
\hline 6051 & (11) & 11 & 0 & 14 & 23 & 10 & (27) & 0 & 22 & 0 \\
\hline 6054 & (16) & 16 & 0 & 14 & 20 & 7 & (15) & 0 & 15 & 0 \\
\hline 6059 & ( 7$)$ & 7 & 0 & 15 & 20 & 6 & (3) & 0 & 3 & 0 \\
\hline 6032 & (15) & 15 & 0 & 16 & 20 & 5 & (26) & 23 & 2 & 0 \\
\hline 6046 & (11) & 11 & 0 & 19 & 21 & 3 & (25) & 25 & 0 & 0 \\
\hline
\end{tabular}

* Sex distribution in each brood was examined in the fish aged more than 50 days following birth. The broods were female unisexual ones born from females $(\mathrm{XX})$ mated with sex-reversed males $(\mathrm{XX})$. F, female; $\mathrm{M}(\mathrm{F})$, sex-reversed male $(\mathrm{XX}) ; \mathrm{M}$, genetic male $(\mathrm{XY})$.

Table 3. Sex distribution of guppies born from females treated with methyltestosterone (MT) for 6 days during gestation

\begin{tabular}{|c|c|c|c|c|c|c|c|c|c|c|}
\hline \multirow{2}{*}{$\begin{array}{l}\text { Fish } \\
\text { No. }\end{array}$} & \multicolumn{3}{|c|}{$\begin{array}{l}\text { Sex distribution } \\
\text { in control brood }\end{array}$} & \multicolumn{3}{|c|}{ Days after the last parturition } & \multicolumn{4}{|c|}{$\begin{array}{l}\text { Sex distribution in } \\
\text { affected brood }\end{array}$} \\
\hline & $\begin{array}{l}\text { (No. } \\
\text { born) }\end{array}$ & $\mathrm{F}$ & $\mathbf{M}$ & $\begin{array}{l}\text { at start } \\
\text { of medication }\end{array}$ & $\begin{array}{l}\text { at end of } \\
\text { medication }\end{array}$ & at parturition & $\begin{array}{l}\text { (No. } \\
\text { born) }\end{array}$ & $F$ & $\mathrm{M}(\mathrm{F})$ & M \\
\hline \multicolumn{11}{|c|}{$400 \mu \mathrm{g} \mathrm{MT} / \mathrm{g}$ diet } \\
\hline 6031 & (9) & 3 & 6 & 11 & 16 & 29 & (34) & 20 & 0 & 14 \\
\hline 6037 & (18) & 11 & 7 & 12 & 17 & 28 & (24) & 15 & 0 & 9 \\
\hline 6030 & $(-)^{* 2}$ & - & - & 12 & 17 & 21 & (29) & 12 & 2 & 15 \\
\hline 6035 & $(17)$ & 8 & 9 & 13 & 18 & 28 & (31) & 14 & 0 & 15 \\
\hline $6036^{* 3}$ & $(10)$ & 10 & 0 & 14 & 19 & 28 & $(42)$ & 42 & 0 & 0 \\
\hline $6059 * 3$ & $(7)$ & 7 & 0 & 15 & 20 & 20 & ( 3$)$ & 0 & 3 & 0 \\
\hline $6033^{* 3}$ & (34) & 34 & 0 & 17 & 22 & 25 & (51) & 15 & 36 & 0 \\
\hline \multicolumn{11}{|c|}{$500 \mu \mathrm{g} \mathrm{MT} / \mathrm{g}$ diet } \\
\hline 6027 & (30) & 17 & 13 & 12 & 17 & 27 & (38) & 18 & 0 & 18 \\
\hline 6043 & $(43)^{* 2}$ & - & - & 17 & 22 & 24 & (12) & 2 & 4 & 6 \\
\hline
\end{tabular}

*1 Sex distribution in each brood was examined in the fish aged more than 50 days following birth. $F$, female; $M(F)$, sex-reversed male; $M$, male.

*2 Newly delivered fish of the control broods were lost by accident.

*3 The females were mated with sex-reversed males to yield all females

lasting shorter than 5 days before parturition were either quite ineffective or partly effective in realizing the functional masculinization of the broods.

In the last series of experiments, treatments of gravid females with 400 and $500 \mu \mathrm{g}$ MT were designed to be completed in 6 days in any period of gestation (Table 3), in order to determine the most adequate time of embryonal life to be effectually responsive to the androgen treatment. It is recognized from the results that the sex reversal was achieved at least in some female offspring only when the 6-day treatments were initiated 6 to 10 days prior to their birth. The 6-day treatments appeared to be insufficient to invert all of the genetic female broods into males except for a case in the treated female No. 6059 
which produced a brood of 3 sex-reversed males only; no difference in the effect was noticed between 400 and $500 \mu \mathrm{g} \mathrm{MT}$. Sex-reversed males of the fish No. 6033 were crossed with virgin females, and successfully fertilized them to bring forth female unisexual broods.

\section{Discussion}

The results of the present study reveal that the oral administration of methyltestosterone (MT) to pregnant guppies is fully efficient in attaining complete and functional masculinization of genetic female offspring if the dosage of MT and the time and duration of treatment are adequately applied. The occurrence of functional masculinization was enough confirmed by mating sex-reversed males with virgin females, which gave birth to all female broods without exception. Furthermore, the effects of a dosage of the androgen to be administered and the time and duration of the treatment adequate to cause functional masculinization were reaffirmed by using these females which were expected to bear all female broods.

Among the dosages of MT tested, $400 \mu \mathrm{g}$ per g diet was evidenced to be sufficient to result in the sex reversal of all female offspring into functional males. A period of treatment during gestation seemed to be much critical; in order to gain regular results, the treatment of gravid females should be carried out continuously for 8 to 10 days before parturition. Longer treatments of gravid females were also effective in obtaining sex-reversed males, but tended to bring about not only maternal disorders, such as a delay of parturition and a death of unborn young, but also an infertility of the resultant sex-reversed males. Although some other sexual disfunctions, involving an atypical formation of gonopodia and an undetermined deficiency in mating as stated by Clemens et al., ${ }^{6)}$ are considered to be evoked by the treatment, a deficiency in the formation and development of sperm ducts is certainly responsible for the infertility of sex-reversed males at least in some instances.

In the guppy, differentiation and development of somatic elements as well as a germinal one in the reproductive system are evidently responsive to androgenic sex hormones. $1,7,8)$ Accordingly, in order to attain a "functional" sex reversal from females to males in the guppy by use of androgens, the treatment should be done in such a manner as to effectuate a harmonized masculinization of both germinal and somatic elements of the reproductive organs. The morphogenetic disorders of sperm ducts and gonopodia as the causes of the infertility in question are admittedly the results of the excessive action of MT which seems to be exposed by the combination of a dosage of hormone and a duration of the hormonal treatment. Even by $300 \mu \mathrm{g}$ MT, the treatment through the last 18 days of gestation, which was necessary to cause but a partial sex reversal of female off'spring at that dosage, elicited a deficient development of sperm ducts in the sex-reversed 
young. The observed obstruction of gestation and parturition in treated females is not an inevitable result of androgen treatments but that of the excessive action of the androgen. For example, a delay of parturition and a birth of dead young occurred when gravid females were treated for 18 days with $300 \mu \mathrm{g}$, for more than 10 days with $400 \mu \mathrm{g}$, and for only 6 days with $500 \mu \mathrm{g} \mathrm{MT}$, though the abnormalities varied in a considerable degree in different treatments.

Comparable cases were mentioned by Dzwillo, ${ }^{2,3)}$ who achieved a functional masculinization of genetic female guppies by immersing gravid females for $24 \mathrm{hr}$ in a water solution of MT at concentration of 3-4 mg per liter water 8 to 12 days prior to parturition. Treatments in earlier days of gestation caused either an interruption of embryogenesis or the production of partially sex-reversed, infertile males; those in later days were without effect in attaining sex reversal. ${ }^{3}$ The treatments carried out during that critical period acted severely on the treated females to provoke a marked delay and obstruction of natural parturition, and a birth of dead young. Viable sex-reversed males failed to mate naturally with females, though they were fertilizable by artificial insemination and yielded all female broods. ${ }^{2}$ The present writer attempted to adopt Dzwillo's method of hormone application in the artificial direction of sex in the guppy and repeatedly observed a sudden death of the treated females. It seems likely that the treatment of gravid females with an intense dosage of MT is too severe to keep them in a healthy condition even though it lasts for only $24 \mathrm{hr}$, and that makes it difficult to obtain stable results following the treatment.

All these facts may emphasize that a shorter treatment with a smaller dosage of MT is needed to make all genetic female offspring successfully sex-reversed into fertile males. From the results of the present study, it is concluded that the conditions are most adequately fulfilled by the oral administration of $400 \mu \mathrm{g}$ MT starting 8 to 10 days prior to parturition and lasting daily up to parturition. The treatment exerted no harmful influences on maternal fish which can yield normal young subsequent to mating; resultant sex-reversed males were fertile to be mated naturally with normal females.

It seems generally accepted that, in order to attain a complete and functional sex reversal in fishes, an administration of sex hormones should be executed to cover enough the stage of indifferent gonads and that of gonadal sex differentiation. ${ }^{91}$ The sex differentiation of the gonad in guppies is known to occur before their birth, in embryos of about $6 \mathrm{~mm}$ in length according to GoOdRICH et al. ${ }^{10)}$ and MIYAMORI. ${ }^{11)}$ This is certainly the cause of the failure of androgen treatments of guppies after birth to induce a complete and functional masculinization. ${ }^{1,6,12,13)}$ In the guppy employed for the present study, gonadal sex differentiation was observed to take place earlier than that cited above: the presence of germ cells in the synaptic stage of meiosis was noticed in genetic female gonads of $4.0-4.5 \mathrm{~mm}$ in body length, about 12 days before birth which was expected to occur 
at the mean interval of about 26 days. Then, the androgen administration starting 8 to 10 days before birth might be unable to cover the period of ovarian sex differentiation. In fact, the present writer's observations disclosed that the gonads of androgen-influenced, genetic females still retained some oocytes shortly after birth, and that these gonads later became entirely transformed into functional testes. Continuous influences of exogenous androgen, through as long as 8 days of the last stage of prenatal life, on female guppies may possibly be essential for enabling their gonads to reverse the genetically determined course of sex differentiation.

It is interesting to note in this context that DzWILLO ${ }^{2}$ succeeded in achieving a functional sex reversal of female offspring by treating gravid guppies with androgen only for $24 \mathrm{hr}$ during a critical period which approximated the one revealed by the present study. It is uncertain whether a single application of an extremely high dosage of androgen can extend its effect on the treated fish long after the withdrawal of hormone or the critical period can be delimited to be much shorter with the elevation of hormone dosages without accompanying any side effects. Detailed histological examinations of the gonads affected by androgen at various stages of pre- and postnatal life may give a promising clue for elucidating these problems.

\section{Acknowledgement}

The present writer wishes to express his gratitude to Prof. K. Yamamoto, Faculty of Fisheries, Hokkaido University, for his continuous interest and criticism throughout the study.

\section{References}

1) H. Takahashi: Bull. Fac. Fish. Hokkaido Univ., 25, 174-199 (1974).

2) M. Dzwillo: Biol. Zentralbl., 81, 575-584 (1962).

3) M. Dzwillo: Zool. Anz., Suppl. 29, 471-476 (1966).

4) C. M. Breder, JR. and C. W. Coates: Copeia, 1932, 147-155 (1932).

5) Ö. WINGE: Nature, 140, 467 (1937).

6) H. P. Clemens, C. MCDermitt and T. Inslee: Copeia, 1966, 280-284 (1966).

7) S. PANDEY: Biol. Reprod., 1, 272-281 (1969).

8) H. TAKaHASHI and Y. IWASAKI: Devel, Growth and Differ., 15, 241-253 (1973).

9) T. Yamamoto: in "Fish Physiology" (ed. by W. S. Hoar and D. J. Randall), Vol. 3, Academic Press, New York, 1969, pp. 117-175.

10) H. B. GoOdrich, J. E. Dee, C. M. FlynN and R. N. Mercer: Biol. Bull., 67, 83-96 (1934)

11) H. Miyamori: J. Biol., Osaka City Univ, 15, 1-22 (1964).

12) T. MOHSEN: Nature, 181, 1074 (1958).

13) H. MiYamori: Zool. Mag., 70, 310-315 (1961). 